\title{
ABSURDITAS ALBERT CAMUS DALAM NOVEL TERJEMAHAN KARYA ZURIYATI MENCARI PEREMPUAN YANG HILANG
}

\author{
Ari Khairurrijal Fahmi*), \\ Uniersitas Muhammadiyah Prof Dr Hamka \\ Correspondences author: Jl Limau II Kebayoran Baru, Jakarta Selatan, Negara; Indonesia \\ e-mail: arikhairurrijal@uhamka.ac.id
}

\begin{abstract}
The aim of this study is to describe depthly about an Albert Camus Absurdity in a translation novel by Prof Zuriyati "Mencari Perempuan yang Hilang". The focus of this research is an expressions and words in the novel which have elements of life uncertainty, feelings of turmoil, and death in Albert Camus's concept. This study uses the Content Analysis method with expressions in the form of sentences as data derived from the novel book " Mencari Perempuan yang Hilang " as a data source. The researcher noted several patterns of expressions found in the novel in the form of uncertainty in life, fluctuations in feelings, to feelings of desire to commit suicide which are manifestations of albert camus's absurdity in real life.
\end{abstract}

Key Words: (Absurdity; Albert Camus; Novel; Mencari Perempuan yang hilang).

Article History: Received: 25/09/2019; Revised: 23/10/2019; Accepted: 22/11/2019; Published: 31/12/2019

How to Cite (MLA 7th): Ari Khairurrijal Fahmi. “Absurditas Albert Camus dalam Novel Terjemahan Karya Zuriyati Mencari Perempuan Yang Hilang." Hortatori Jurnal Pendidikan Bahasa dan Sastra Indonesia vol.3 no.2 (2019): 81-90. Print/Online. Copyrights Holder: Ari Khairurrijal Fahmi. First Publication: Hortatori Jurnal Pendidikan Bahasa dan Sastra Indonesia (2019).

\section{Pendahuluan}

Gejala kemanusiaan yang ada didunia ini selalu direpresentasikan dengan karya sastra. Sisi kehidupan manusia bisa diperkenalkan oleh beragam karya sastra. Tidak semua pengalaman dan sisi kehidupan manusia itu terlihat indah, bisa jadi pengalaman manusia itu berupa hal yang abstrak, aneh, liar, bahkan mungkin Absurd. Banyak makna yang tersimpan dalam pengalaman manusia tersebut, yang perlu di telaah melalui sastra.

Sebuah karya seni yang indah bermula dari ketertarikan seseorang dalam menelaah karya sastra. kreativitas pengarang merupakan sebuah karya sastra yang bukan sebuah imitasi. Karya sastra merupakan sesuatu yang kompleks dan rumit. (Yulistio, 2015)

Menelaah sebuah karya sastra sama dengan menggali nilai-nilai dari karya tersebut sebagai ilmu pengetahuan yang bersifat empiris. Dalam buku nya Welek mengatakan bahwa studi mendalam terhadap karya sastra ini dapat dilakukan melalui dua macam pendekatan, yakni instrinsik dan ekstrinsik.(Welek \& Waren, 1993). Salah satu karya sastra yang selalu menjadi objek penelitian adalah Novel.

Didalam Novel "mencari perempuan yang hilang" pembahasan konflik-konflik sosial dapat ditemukan, baik berupa pembentukan strata sosial ataupun penggambaran kekuasaan yang berfokus pada kekuasaan yang membolehkan semua cara demi harta.

Novel yang ditulis oleh DR. Imad Zaki, dan diterjemahkan oleh Prof. Dr. Zuriyati dengan judul "Mencari Perempuan yang Hilang" menceritakan kisah sedih seorang wanita yang menghilang dari 
peradaban karena memiliki beban berat yang dihasilkan dari kejahatan ayahnya yang merugikan orang banyak. Novel ini berkisah tentang seorang wanita yang menghilang dari peradaban karena tidak jadi menikah dengan kekasih pujaan hati karena arogansi sang Ayah, nan ambisius dan serakah. Tidak hanya itu, novel ini juga mengisahkan seorang anak kandung yang tidak dididik dengan benar dan penuh kasih sayang oleh orang tuanya. Konflik yang dialami dalam tokoh-tokoh utama adalah konflik batin, konflik antarindividu, dan kelompok. Konfliknya terjadi karena disebabkan oleh kejahatan, kecurangan, ketidakjujuran, kesalahpamahan, dan keserakahan.

Dalam novel tersebut terdapat berbagai konteks yang dapat dikaji seperti konteks sosial dari hubungannya dengan masyarakat atau budaya dan politik tertentu. Konteks ini menjelaskan bagaimana peristiwa dan teks wacana memunculkan bentuk-bentuk absurditas kehidupan serta menjelaskan bagaimana hubungan antara teks didalam novel tersebut dengan kondisi absurditas masyarakat itu sendiri sebagai faktor yang menanamkan kondisi yang sebenarnya.

Kajian Absurditas telah dikaitkan dengan filsafat eksistensialisme. Dengan kata lain, eksistensialisme menjadi dasar dari pemikiran absurditas. Istilah eksistensialisme sendiri bisa memiliki arti sebagai berikut: pada tingkat paling dasar, istilah eksist itu merupakan sikap terhadap kehidupan manusia yang menekankan pada pengalaman hidup, nyata dan langsung dari tiap-tiap orang. Filsafat ini memperhatikan cara orang berinteraksi dengan orang lain dan kesepemahaman tentang sikap masingmasing. Sedangkan dalam arti yang lebih jauh, istilah tersebut mengacu kepada sebuah gerakan pada tahun 1938-1968.

Absurd juga diartikan sebagai kondisi manusia yang tidak mampu menetapkan tujuan hidupnya dan juga tidak bisa membuat kehidupannya memiliki makna, bahkan absurtditas secara khusus diartikan sebagai kondisi manusia yang tidak mengerti apa itu kehidupan dan untuk apa manusia hidup. Bagi Albert Camus, ketidakjelasan tujuan hidup adalah hal yang absurd.

Penelitian tentang absurditas telah dilakukan oleh beberapa orang diantaranya; Turrahmat dan Jupriyanto, penelitian dengan judul "Absurdisme Indonesia dalam "Sumur Tanpa Dasar" karya Arifin C Noer. Hasil penelitian ini menunjukkan bahwa Kisah hidup manusia atau tokoh dalam naskah drama ini terombang-ambing dalam ketidakpastian. Ketiga, jalan cerita pada naskah drama STD ini berisi peristiwaperistiwa yang masih bisa dirunut alurnya. Eksistensi Tuhan tetap muncul dalam naskah drama ini. JejakJejak kekuasaan Tuhan juga tampak berkelindan di beberapa dialog. (Turahmat \& Jupriyanto, 2017)

Penelitian selanjutnya telah dilakukan juga oleh Slamet Riyadi. Dengan judul Absurditas dalam drama Dag dig dug. Hasil penelitian ini adalah (1) absurditas perilaku dalam drama Dag Dig Dug karya Putu Wijaya dimunculkan oleh tokoh suami, istri, tamu, Cokro, dan Ibrahim yang aneh; (Riyadi, Ridlwan, \& Affandy, 2018)

\section{Novel Mencari Perempuan yang Hilang}

Dalam peelitian ini penulis memfokuskan pada Absurditas Albert Camus dalam novel Mencari perempuan yang hilang. Novel Mencari Perempuan yang hilang dihadirkan oleh penulis asli dan diterjemahkan oleh Prof Dr Zuriyati, M.Pd dengan mengangkat kisah cinta antara tokoh Sholeh dan tokoh wanita bernama Ahlam, sholeh adalah seorang dokter yang ahli dibidangnya serta berstatus sebagai lulusan cum laude di universitas kedokteran, ia bekerja di rumah sakit Ibnu Nafis, rumah sakit tempat berkumpulnya dokter spesialis.

Mencari perempuan yang hilang adalah kisah tentang seorang wanita yang menghilang dari sebuah peradaban karena menanggung beban kejahatan ayah kandungnya. Mencari perempuan yang hilang juga merupakan kisah seorang wanita yang menghilang dari peradaban karena tidak menikahi kekasih pujaan hati nya karena sikap ayahnya yang arogan, ambisius serta serakah, dan kisah seorang anak yang tidak di didik dengan benar dan penuh kasih sayang oleh orang tuanya.

2. Absurditas

Absurd merupakan aliran sastra yang mengalami perkembangan selepas Perang Dunia II. Jika kita melakukan penelusuran mendalam, ternyata perkembangan Absurditas ini masih satu rumpun dengan aliran eksistensialisme, yang telah memiliki sejarah panjang, bahkan sebelum Perang Dunia I. Tokoh eksistensialis dan juga peletak dasar eksistensialisme, Kierkegaard (1813-1855), telah

menulis karya-karyanya sebelum Perang Dunia I. (Sumiyadi, 2010): Kadang-kadang filsafat dan sastra menjadi satu. Filsafat dapat diucapkan lewat sastra, sementara sastra itu sendiri sekaligus dapat bertindak sebagai filsafat. Sesudah Perang Dunia II, misalnya

Albert Camus dan Jean Paul Sartre adalah filsuf eksistensialisme yang sekaligus adalah sastrawan. 
Novel-novel mereka adalah pengucapan filsafat, dan sekaligus juga filsafat. Dalam sebuah kajian yang lain sisi historis absurdisme dicetuskan kali pertama oleh Albert Camus, seorang filsuf sekaligus sastrawan Prancis. Albert Camus adalah seorang ateis yang tidak percaya adanya Tuhan. Ketidakpercayaannya terhadap Tuhan inilah yang menjadi pondasi paham absurdisme. Absurditas dianggap sebagai sebuah simpul pemikiran eksistensialisme yang dikembangkan oleh Albert Camus menjadi sebuah filsafat yang mandiri. Dengan kata lain absurdisme merupakan aliran yang berawal dari pemikiran eksistensialisme. Filsafat eksistensialisme ini dimanifestasikan menjadi pondasi dalam penulisan naskah-naskah drama.(Darma, 2004). Dalam Kamus Inggris-Indonesia karangan Echols and shadily (1990:4) bahwa absurditas atau "absurdity" berarti kemustahilan, keadaannya yang bukanbukan. Karya sastra absurd ialah karya sastra (dalam drama dan cerita rekaan) yang berlandaskan anggapan bahwa pada dasarnya kehidupan manusia itu absurd. (Panuti, 1984) Sastrapratedja berpendapat bahwa absurditas digambarkan sebagai kontradiksi-kontradiksi antara dunia yang irrasional dengan keinginan manusia akan kejelasan. (Sastrapratedja, 1982) Pengertian Absurditas dalam Encyclopedia of knowledge menunjukkan keterkaitan pemikiran absurditas diawali dengan pemikiran eksistensialisme, seperti yang dikutip berikut:

"Absurdity is an idea commonly associated with existensialisme, beginning the 19th century, mainly through the influence of S. Kierkegaard. Religion was often described as absurd because it could not be justified on rational principles; rather it was consider as based on that Kierkegaard called " a leap of faith."

Absurditas adalah sebuah ide yang umumnya diasosiasikan dengan eksistensialisme, dimulai dari abad 19 terutama diinspirasikan dari Soren Kierkegaard. Religiusitas selanjutnya dijabarkan sebagai yang absurd karena tidak bisa disamakan kepada prinsip rasional; agaknya ditimbang dari landasan Kierkegaard yang disebut lompatan iman.

\section{Absurditas Albert Camus}

Konsep absurd yang berbeda dikenalkan oleh Albert Camus dalam esainya yang berjudul Mite Sisifus (Camus, 1955) yang ditulis pada tahun 1941 dan diterbitkan pada tahun 1942. Camus bukanlah penemu absurditas. Intuisi mengenai absurd sudah ada sejak sebelum perang dunia I yang dikenalkan melalui tokoh eksistensialisme Nietzsche, Kierkegaard, Husserl, dan Jaspers. Albert Camus menggunakan cara berbeda dengan pendahulunya. Camus menghubungkan mata rantai eksistensialisme dengan absurditas.

Inti cerita Mitos sisifus dirujuk dari cerita mitologi dari zaman Yunani kuno. Dikisahkan dalam cerita tersebut bahwa seorang yang bernama Sisifus dihukum para oleh dewa. Hukuman yang harus dilakukan Sisifus ialah mengangkat batu besar yang berakhir di atas sebuah gunung, batu itu turun kembali dengan cara menggelinding, kemudian Sisifus mengangkut batu itu kembali ke puncak. Hukuman itu terus berulang dilakukan oleh Sisifus. Hukuman Sisifus dimaknai oleh Camus sebagai amsal hidup manusia. (Bagus, 2000).

Peneliti merumuskan bahwa Albert Camus memngkonsepkan absurditas kedalam beberapa point

\section{a. Ketidakpastian}

Ada ungkapan yang menarik dari Albert Camus; bagi Camus, ketidakjelasan tujuan hidup adalah hal yang absurd. Absurd didefinisikan sebagai kondisi manusia yang tidak mampu menetapkan tujuan dan makna hidupnya, secara khusus diartikan kondisi manusia tidak mengerti apa itu kehidupan dan untuk apa manusia hidup.

Sebagai contoh: manusia tidak dapat mengetahui apa yang akan terjadi dimasa yang akan datang, ketika gambaran masa depan masih begitu abstrak manusia selalu menantikannya. Camus menerangkan melalui sosok Meursault (Salah satu tokoh dalam Novel) bahwa dalam kehidupan ini banyak sekali yang tidak bisa dipahami dan terlampau tidak wajar seperti contoh tentang masa depan yang abstrak tersebut, dan Meursault memiliki kesadaran akan itu sehingga ia memilih menjalani hidup sebagai mana adanya tanpa menganggap hidup adalah sesuatu yang hebat. Manusia yang absurd, seperti Meursault, adalah manusia yang hidup untuk masa ini dan meninggalkan masa lampau maupun masa depan. 


\section{b. Perasaan}

Salah satu hal yang absurd adalah perasaan, karena pada hakikatnya perasaan bersifat tidak mutlak dan tidak jelas, tidak rasional dan tidak irasional, dipenuhi dengan kontradiksikontradiksi yang bertentangan. Perasaan sendiri tidak memiliki batasan tegas dan mutlak pada penggambaran suasana pada realitas. Ia tidak bersifat tenang atau dinamis, melainkan tak terarah dengan jelas. Ini sungguh absurd.

\section{c. Tuhan}

Dalam definisi Albert Camus, Tuhan adalah ketika manusia bernafsu pada kerinduan tersebut untuk mengungkap sesuatu yang sesungguhnya tak dapat terungkap. Pada persoalan "Yang Absurd" yang kini menjadi Tuhan, Camus mengutip pernyataan-pernyataan dari Lev Shestov. Dari Shestov, Camus menulis, "Satu-satunya jalan keluar yang benar adalah justru di mana menurut penilaian manusia tidak ada jalan keluar. Jika tidak, mengapa kita membutuhkan Tuhan? Kita hanya berpaling kepada Tuhan untuk memperoleh hal yang tidak mungkin. Sedangkan untuk hal yang mungkin manusia saja sudah cukup" (Camus, 1993: 42). Manusia selalu berserah diri kepada tuhannya. Absurd ketika melihat manusia berpegang penuh pada sebuah harapan atau kerinduan akan kesatuan dan seakan-akan menegasikan realitas. Melepaskan diri pada belenggu ilusi-ilusi rasional dan menerima "Yang Absurd" bersamaan dengan absurditas adalah absurd. Tentu saja kita dihadapkan pada posisi yang serba salah di mana segala yang rasional absurd dan di luarnya adalah kosong, dan menggantungkan sesuatu pada harapan juga adalah absurd.

\section{d. Kematian}

"Should I kill myself, or have a cup of coffee?" (Albert Camus)

Berbeda dengan perasaan dan tuhan, kematian merupakan satu satunya hal yang tidak Absurd. Karena menurutnya kematian adalah suatu kepastian. Menurutnya "Yang Absurd" tetap ada dan itu adalah sesuatu yang terjadi sebelum kematian itu datang. Akibat kepastian dari kematian menyebabkan "Yang Absurd" kian membesar dan mengalahkan beberapa orang dengan memutuskan untuk bunuh diri, dengan harapan dapat memutus rantai absurditas.

Banyak orang menduga bahwa perbuatan bunuh diri biasanya disebabkan oleh depresi yang merasa bahwa hidup tidak layak untuk dijalani. Ada juga bunuh diri yang disebabkan sebuah gagasan atau ilusi yang diyakini memberikan kehidupan, contohnya bom bunuh diri dengan keyakinan masuk surga. Pada kasus seperti ini, makna hidup adalah pertanyaan yang mendesak sekaligus mendasar, Mereka (yang bunuh diri) terlebih menyadari kekosongan makna hidup dan tidak sanggup menerima kenyataan tersebut. Tinggal dua pilihan yang mereka lakukan secara ekstrem yaitu memutus absurditas atau mengejar kerinduan akan kesatuan, dengan bergantung pada kepastian (yang dipercepat).(Camus, 1993: 71).

\section{Metode}

Metode yang digunakan dalam penelitian ini adalah metode deskriptif kualitatif dengan teknik analisis isi. Konstruk analisis isi diperoleh dari 1) praktek-praktek atau teori yang ada, 2) pengetahuan atau pengalaman dari para ahli, dan 3) penelitian sebelumnya . Kemudian ketiga proses ini dirumuskan kembali sebagai bentukan nilai yang terdapat dalam percakapan, pernyataan, serta bentuk metaphor dan tatabahasa lainnya (modalitas). Dari beberapa bentuk linguistik tersebut ditarik kesimpulan berupa situasi dari pesapa dan penyapa yang menandakan lingkup latar belakang dari kondisi sosial dalam teks.

Metode analisis isi dalam teks novel ini dibagi dalam dua tahapan analisis, yakni analisis teks secara sintagmatis dan paradigmatis. Analisis teks yang pertama adalah secara sintagmatis adalah wacana yang mengeksplorasi struktur bahasa untuk menarik kesimpulan-kesimpulan hasil analisisnya. Ada dua jenis bentuk teks secara sintagmatis yang dipakai dalam penelitian ini.

1. Metode Analisis Percakapan (AP)

Metode ini bertujuan untuk menemukan prinsip dan prosedur yang dipergunakan pertisipan dalam memproduksi struktur dan aturan dari suatu situasi komunikasi. Dalam perspektif metode ini suatu percakapan antara dua orang atau lebih dianalisis dengan memperhatikan cara mereka berinteraksi seperti pola giliran dalam percakapan dan situasi komunikasi yang terjadi. 


\section{Metode Pragmatik Fungsional (PF)}

Metode ini membahas bentuk tuturan (Speech Action) dan tindak tutur (Speech act) untuk menemukan tujuan dari partisipan dalam sebuah percakapan. Cara kerja metode ini difokuskan pada psedural dan pola percakapan. Prosedural yang dimaksud adalah satuan unit terkecil dari tindakan percakapan seperti penggunaan pronominal saya atau deiksis di sini dan sekarang .

\begin{tabular}{|c|c|c|c|c|}
\hline No & Halaman & Ungkapan & Sub Judul & $\begin{array}{c}\text { Albert Camus's } \\
\text { Absurdity }\end{array}$ \\
\hline 1 & & & & \\
\hline 2 & & & & \\
\hline
\end{tabular}

\section{Hasil dan Diskusi}

Hasil dan Diskusi Dalam pembahasan hasil penulis mengelompokkan hasil kedalam konsep konsep absurditas Albert camus.

\section{A. Ketidakpastian}

1. Analisis Data No 16, Halaman 335, Subjudul; Kesaksian Dokter Syarif,

Aku pergi ke Amerika untuk melanjutkan studi dan meraih gelar doktor secepatnya. Dengan nilai sangat memuaskan, aku kembali ke tanah air. Aku datangi setiap kantor besar untuk memasukkan lamaran. Aku ingin bekerja dikantor besar agar gajiku juga besar. Gaji yang besar adalah tujuan utamaku agar aku dapat membiayai keluarga sesuai dengan impianku selama ini. Tetapi kenyataannya ijazah dengan nilai memuaskan saja tidak bisa mewujudkan impian. Masih banyak pemilik ijazah yang menunggu gilirannya di bilangan anak tangga.

Sebagai sebuah analisis, ungkapan diatas menunjukkan proses yang tidak berjalan sesuai dengan keinginan, hal itu dibuktikan dengan ungkapan bahwa meskipun sudah mendapatkan gelar dokter dan gaji yang besar, namun itu semua tidak sesuai dengan harapannya.

Dalam hal ini absurditas albert camus terlihat bahwa ketidakpastian dalam hidup itu tertananm dalam tokoh novel tersebut.

2. Analisis Data No 16, Halaman 335, Subjudul; Kesaksian Dokter Syarif,

Aku pergi ke Amerika untuk melanjutkan studi dan meraih gelar doktor secepatnya. Dengan nilai sangat memuaskan, aku kembali ke tanah air. Aku datangi setiap kantor besar untuk memasukkan lamaran. Aku ingin bekerja dikantor besar agar gajiku juga besar. Gaji yang besar adalah tujuan utamaku agar aku dapat membiayai keluarga sesuai dengan impianku selama ini. Tetapi kenyataannya ijazah dengan nilai memuaskan saja tidak bisa mewujudkan impian. Masih banyak pemilik ijazah yang menunggu gilirannya di bilangan anak tangga.

Sebagai sebuah analisis, ungkapan diatas menunjukkan proses yang tidak berjalan sesuai dengan keinginan, hal itu dibuktikan dengan ungkapan bahwa meskipun sudah mendapatkan gelar dokter dan gaji yang besar, namun itu semua tidak sesuai dengan harapannya.

Dalam hal ini absurditas albert camus terlihat bahwa ketidakpastian dalam hidup itu tertananm dalam tokoh novel tersebut.

\section{B. Perasaan}

1. Analisis Data No 15, Halaman 223, Subjudul; Simalakama,

Keraguan membuatku terombang ambing bagaikan orang gila. Keraguan memusnahkan semua kenanganku tentang kekasih. Keraguan mulai mencari cari kesalahan yang tersembunyi.

Berdasarkan konsep dasar albert camus terkait dengan absurditas, ungkapan dalam novel ini menyebutkan bahwa keraguan membuat tokoh dalam novel ini terombang ambing dalam ketidak pastian dan semua kenangan tentang kekasih.

Dalam ungkapan tersebut disebutkan bahwa kenyataan hidup yang selalu pahit selalu menyelimuti hidup tokoh dalam novel. Dalam hal ini konsep absurditas albert camus yang sesuai adalah absurditas perasaan dan kegalauan

2. Analisis Data No 9, Halaman 52, Subjudul; Dunia Serigala,

"Sudah berapa banyak kenyataan hidup ini menerpaku. Kenyataan pahit itu senantiasa bersemayam di dadaku seperti bayang bayang yang mencengkramkan kuku kukunya dalam jiwaku. Seolah hanya aku saja yang berdosari” 
Berdasarkan konsep dasar albert camus terkait dengan absurditas, ungkapan dalam novel ini menyebutkan bahwa banyak kenyataan hidup yang ini menerpa tokoh novel. Kenyataan pahit itu senantiasa bersemayam di dadanya seperti bayang bayang yang mencengkramkan kuku kukunya dalam jiwanya. Seolah hanya ia saja yang berdosa.

Dalam ungkapan tersebut disebutkan bahwa kenyataan hidup yang selalu pahit selalu menyelimuti hidup tokoh dalam novel. Dalam hal ini konsep absurditas albert camus yang sesuai adalah absurditas perasaan dan kegalauan.

\section{Kematian}

\section{Analisis Data No 3, Halaman 17, Subjudul; Kantin Paman Darwis,}

"Dikala manusia tidak memiliki harta, dia mengira bahwa kebahagiaan ada didalam harta, di dalam istana dan di dalam mobil mewah. Tapi, setelah mereka memiliki semua itu, dia tidak menemukan kebahagiaan. Dia merasa gagal, terasing dan kehilangan kepercayaan terhadap hidup ini bahkan ada yang ingin bunuh diri”

Berdasarkan konsep dasar albert camus terkait dengan absurditas, ungkapan dalam novel ini menyebutkan bahwa Dikala manusia tidak memiliki harta, dia mengira bahwa kebahagiaan ada didalam harta, di dalam istana dan di dalam mobil mewah. Tapi, setelah mereka memiliki semua itu, dia tidak menemukan kebahagiaan. Dia merasa gagal, terasing dan kehilangan kepercayaan terhadap hidup ini bahkan ada yang ingin bunuh diri.

Dalam ungkapan tersebut disebutkan bahwa harta tidak membawa kebahagiaan, dan bagi yang merasa gagal dalam kebahagiaan karena harta akan memiliki kecenderungan untuk bunuh diri

Dalam hal ini konsep absurditas albert camus yang sesuai adalah absurditas ketidakpastian hidup dan kematian (bunuh diri).

\begin{tabular}{|c|c|c|c|c|}
\hline $\begin{array}{l}\text { No } \\
\text { Data }\end{array}$ & Halaman & Ungkapan & Sub Judul & $\begin{array}{c}\text { Albert Camus's } \\
\text { Absurdity }\end{array}$ \\
\hline 1 & 13 & $\begin{array}{l}\text { "Kalau begitu, bagaimana } \\
\text { kalau aku dan hanin jadi } \\
\text { bintang pelawak saja" }\end{array}$ & Kantin paman Darwis & perasaan \\
\hline 2 & 15 & $\begin{array}{l}\text { "Kekecewaan itulah yang } \\
\text { membuat perasaannya halus } \\
\text { dan lembut }\end{array}$ & Kantin paman Darwis & Perasaan \\
\hline 3 & 17 & $\begin{array}{l}\text { "Dikala manusia tidak } \\
\text { memiliki harta, dia mengira } \\
\text { bahwa kebahagiaan ada } \\
\text { didalam harta, di dalam } \\
\text { istana dan di dalam mobil } \\
\text { mewah. Tapi, setelah } \\
\text { mereka memiliki semua itu, } \\
\text { dia tidak menemukan } \\
\text { kebahagiaan. Dia merasa } \\
\text { gagal, terasing dan } \\
\text { kehilangan kepercayaan } \\
\text { terhadap hidup ini bahkan } \\
\text { ada yang ingin bunuh diri }\end{array}$ & Kantin paman Darwis & $\begin{array}{l}\text { Ketidakpastian } \\
\text { dan kematian }\end{array}$ \\
\hline
\end{tabular}




\begin{tabular}{|c|c|c|c|c|}
\hline 4 & 23 & $\begin{array}{l}\text { Aku bertanya padanya } \\
\text { sambil membasahi kapas } \\
\text { dengan alkohol, ; "Punya } \\
\text { penyakit diabetes?" } \\
\text { "tidak", "anda sakit jiwa?", } \\
\text { "Ya, Selalu" }\end{array}$ & Hati yang terbelah & Perasaan \\
\hline 5 & 42 & $\begin{array}{l}\text { Aku tetap tidak yakin } \\
\text { bahwa } \\
\text { membuat seorang ibu tega } \\
\text { membuang } \\
\text { kandungnya. Jangan lupa } \\
\text { bahwa ibu itu juga } \\
\text { meninggalkan uang yang } \\
\text { tidak sedikit jumlah nya. }\end{array}$ & Singa yang terluka & Ketidakpastian \\
\hline 6 & 48 & $\begin{array}{l}\text { Sekarang zaman edan, } \\
\text { zaman yang aneh, penuh } \\
\text { bara dan konflik. Seakan } \\
\text { akan dunia ini semakin } \\
\text { sempit sehingga tidak ada } \\
\text { lagi tempat untuk kejujuran } \\
\text { dan nilai nilai moral. }\end{array}$ & Dunia serigala & ketidakpastian \\
\hline 7 & 51 & $\begin{array}{l}\text { Bumi ini sudah sempit } \\
\text { untuk kita. Sempit dan } \\
\text { tidak bisa diperluas lagi } \\
\text { untuk menampung air mata } \\
\text { kita. }\end{array}$ & Dunia serigala & Ketidakpastuan \\
\hline 8 & 51 & $\begin{array}{l}\text { Kadang-kadang aku ingin } \\
\text { berteriak. Aku ingin } \\
\text { mengabarkan kepada alam } \\
\text { raya bahwa banyak orang } \\
\text { yang berteriak teriak } \\
\text { bagaikan orang gila untuk } \\
\text { menutupi kebodohannya. }\end{array}$ & Dunia serigala & Perasaan \\
\hline 9 & 52 & $\begin{array}{l}\text { Sudah berapa banyak } \\
\text { kenyataan } \quad \text { hidup ini } \\
\text { menerpaku. }\end{array}$ & Dunia serigala & Perasaan \\
\hline
\end{tabular}




\begin{tabular}{|c|c|c|c|c|}
\hline & & $\begin{array}{l}\text { pahit itu senantiasa } \\
\text { bersemayam di dadaku } \\
\text { seperti bayang bayang yang } \\
\text { mencengkramkan kuku } \\
\text { kukunya dalam jiwaku. } \\
\text { Seolah hanya aku saja yang } \\
\text { berdosa }\end{array}$ & & \\
\hline 10 & 111 & $\begin{array}{l}\text { Semoga aku dapat } \\
\text { menjalani sisa hidup ini } \\
\text { untuk hal hal yang berguna. }\end{array}$ & Mahkamah & Kematian \\
\hline 11 & $131-132$ & $\begin{array}{l}\text { Menurutmu apa yang } \\
\text { paling kejam didunia ini. } \\
\text { kekejaman yang paling } \\
\text { sadis adalah bertengkar } \\
\text { dengan orang kita cintai }\end{array}$ & Ayahku Bunglon & Perasaan \\
\hline 12 & 178 & $\begin{array}{l}\text { Kesempatan hanya sekali } \\
\text { dalam hidup, untuk itu } \\
\text { kejarlah! Rampaslah semua } \\
\text { kesempatan karena dia } \\
\text { tidak akan pernah kembali. }\end{array}$ & Mengertilah Ahlam & Ketidakpastian \\
\hline 13 & 194 & $\begin{array}{l}\text { Memang dunia bisnis itu } \\
\text { mengasyikkan, bagaikan } \\
\text { api yang membakar daun } \\
\text { daun kering. Bisnis bisa } \\
\text { membuat orang lupa } \\
\text { daratan. Dengan uang kau } \\
\text { bisa membeli apa saja } \\
\text { termasuk kebahgiaan }\end{array}$ & Sekretaris Bayaran & Ketidakpastian \\
\hline 14 & 201 & $\begin{array}{l}\text { Maksudku bahwa tugas } \\
\text { dokter masih merupakan } \\
\text { pekerjaan yang merugikan. } \\
\text { Jumlah dokter semakin } \\
\text { banyak, tapi tidak seorang } \\
\text { pun terlihat kaya raya }\end{array}$ & Sekretaris Bayaran & ketidakpastian \\
\hline 15 & 223 & $\begin{array}{lr}\text { Keraguan } & \text { membuatku } \\
\text { terombang } & \text { ambing }\end{array}$ & Simalakama & ketidakpastian \\
\hline
\end{tabular}




\begin{tabular}{|c|c|c|c|c|}
\hline & & $\begin{array}{l}\text { bagaikan orang gila. } \\
\text { Keraguan memusnahkan } \\
\text { semua kenanganku tentang } \\
\text { kekasih. Keraguan mulai } \\
\text { mencari cari kesalahan } \\
\text { yang tersembunyi. }\end{array}$ & & \\
\hline 16 & 335 & $\begin{array}{l}\text { Aku pergi ke Amerika } \\
\text { untuk melanjutkan studi } \\
\text { dan meraih gelar doktor } \\
\text { secepatnya. Dengan nilai } \\
\text { sangat memuaskan, aku } \\
\text { kembali ke tanah air. Aku } \\
\text { datangi setiap kantor besar } \\
\text { untuk memasukkan } \\
\text { lamaran. Aku ingin bekerja } \\
\text { dikantor besar agar gajiku } \\
\text { juga besar. Gaji yang besar } \\
\text { adalah tujuan utamaku agar } \\
\text { aku dapat membiayai } \\
\text { keluarga sesuai dengan } \\
\text { impianku selama ini. Tetapi } \\
\text { kenyataannya ijazah dengan } \\
\text { nilai memuaskan saja tidak } \\
\text { bisa mewujudkan impian. } \\
\text { Masih banyak pemilik } \\
\text { ijazah yang menunggu } \\
\text { gilirannya di bilangan anak } \\
\text { tangga. }\end{array}$ & $\begin{array}{l}\text { Kesaksian Doktor } \\
\text { Syarif }\end{array}$ & ketidakpastian \\
\hline
\end{tabular}

\section{Simpulan}

Berdasarkan hasil penelitian dan pembahasan beserta analisis ungkapan ungkapan dalam Novel mencari perempuan yang hilang, penulis memberikan kesimpulan sebagai berikut :

Dalam novel mencari perempuan yang hilang, Konsep Absurditas Albert camus tergambar dengan adanya beberapa ungkapan, kondisi, dan narasi yang didapat oleh Peneliti. Absurditas tersebut terbagi dalam beberapa konsep albert camus. 1). Ketidakpastian Dapat diartikan sebagai kondisi di mana manusia tidak mampu menetapkan tujuan dan makna bagi hidupnya. Dalam novel mencari perempuan yang hilang ditemukan dan dianalisis lebih dari 9 buah data berupa teks yang mengungkapkan ketidakpastian hidup. 2) Perasaan dalam konsep Camus merupakan hal absurd, karena sejatinya perasaan tidak bersifat mutlak dan tidak bersifat jelas, tidak menjadi rasional dan juga tidak menjadi irasional. Dalam novel mencari perempuan yang hilang ungkapan mengenai perasaan ditemukan dan diungkapkan 
sebanyak 5 kali. 3)Kematian yang dimaksud merupakan kematian yang disengaja sebagai buah dari keputusasaan. Dalam novel mencari perempuan yang hilang ditemukan 2 ungkapan yang dapat menunjukkan bahwa potensi bunuh diri dapat terjadi.

\section{Daftar Rujukan}

Camus, Albert. The Myth Of Sisyphus And Other Essays. 1955.

Darma, Budi. Pengantar Teori Sastra. 2004.

Panuti, Sudjiman. Kamus Istilah Sastra. Gramedia, 1984.

Riyadi, Slamet, et al. "ABSURDITAS DALAM DRAMA DAG DIG DUG KARYA PUTU WIJAYA DAN NOVEL PAYUDARA KARYA CHAVCHAY SYAIFULLAH ( SASTRA PERBANDINGAN )." Lingua Franca, Jurnal Bahasa, Sastra, Dan Pengajarannya, vol. 6, no. 1, 2018, pp. 111-19.

Sastrapratedja. Manusia Multi Dimensional. Gramedia, 1982.

Sumiyadi. "MAZHAB SASTRA : ABSURDISME." Jurdiksatrasia, FPBS UPI, vol. 2, no. 3, 2010, pp. 1-32.

Turahmat, and Jupriyanto. "ABSURDISME INDONESIA DALAM 'SUMUR TANPA DASAR' KARYA ARIFIN C. NOER.” Jurnal Pendidikan Bahasa Indonesia, vol. 5, no. 1, 2017, pp. 83-98.

Welek, Rene, and AUstin Waren. Teori Kesusastraan. Gramedia, 1993.

Yulistio, Didi. "Model Kajian Absurditas Eksistensialisme Manusia Dalam Novel Sampar Albert Camus." Prosiding Seminar Nasional Bulan Bahasa UNIB 2015, 2015, pp. 37-54. 